\title{
The three pillars of bioentrepreneurship
}

\section{Creating a biotechnology company that lasts depends on the ability to balance management, capital, and technology.}

\author{
Hubert J. P. Schoemaker and Anne Faulkner Schoemaker
}

History has proven that starting a new biotechnology company is not an activity for the faint of heart. Neither is it an endeavor that can be undertaken without patience, perseverance, or optimism at their extremes. However, no matter how strong your character, there are three structural elements that are absolutely necessary for biotechnology success. We call these the "three pillars" of bioentrepreneurship: a quality management team, adequate financing, and access to new technology that leads to products.

While establishing these pillars to support your company is difficult, maintaining them over time is an even bigger challenge. Each of these pillars must function in synergy over periods of up to 10 years or longer and, by retrospective analysis, it is clear that any weakness within the first critical decade will determine the future of the entrepreneurial biotechnology company. Because most companies do not achieve "first-tier" status if they have a demonstrable weakness in one of the three pillars, the importance of each of these structures within the context of the industry warrants independent examination.

\section{Management}

The management pillar is the first to be secured in any new biopharmaceutical company. No transformation of technology opportunity into product sale can ever occur without skilled managerial capability. However, having said this, there is a sobering truth to be addressed: A chief executive officer and management team equipped to run a biotechnology company from startup through commercialization are one of the scarcest resources in the industry. Consequently, management is often the

Hubert J. P. Schoemaker is chairman of the board of Centocor, Inc., 200 Great Valley Parkway, Malvern, PA 19355 (schoemakerh@centocor.com) and Anne Faulkner Schoemaker is a technology licensing consultant

(AnneFaulkner@worldnet.att.net). weakest pillar in most biotechnology companies.

This is largely because the repertoire of managerial skills required to navigate the company successfully from startup through full integration is so wide ranging. Take, for example, the startup. The company's earliest management team may consist of only a scientific founder and a businessperson. During that period, the critical managerial skill sets include the ability to direct a research and development organization and the ability to communicate the company's promise to the financial community.

If a company succeeds through the initial phases and begins commercial operation, the next set of management skills it must acquire, either internally or externally, are manufacturing and commercialization capabilities. At the same time, managerial focus should also be directed toward collaboration as the company positions itself for growth.

Since few biotechnology companies in the early stages of development can internally develop a full range of operating capabilities, the precise nature of these relationships, and the timing of their implementation, must be carefully managed for their impact on the company. Marketing and sales agreements, in particular, critically affect the profit and loss statement, and the unfavorable timing of their execution can have a lasting negative effect on the bottom line.

While all of these deals are being developed, the judicious allocation of resources within the company is a managerial imperative at all times. There are numerous examples of companies that have commercialized products well but, absent sufficient internal investment in $\mathrm{R} \& \mathrm{D}$, have inadequately fueled their product pipelines. Conversely, other management teams have built impres- sive $R \& D$ enterprises but have failed to bring a single product to commercial fruition.

From this sketch of typical managerial responsibilities during the building of a company, it is quite apparent that the set of skills a startup company's very existence may depend on will become significantly less important to the enterprise 10 years down the road. The appropriate allocation of corporate resources, as the company transitions from an $\mathrm{R} \& \mathrm{D}$-driven to a market-driven culture is a lasting managerial challenge that heavily taxes all management teams.

\section{Capital}

Capital forms the second pillar of any biotechnology company. It is unequivocally true that, at the early stages, a biotechnology company can never have too much of this resource. Undercapitalization and a weak $\mathrm{CEO}$ are the root causes of most biotechnology company failures. Being opportunistic in the marketplace when financial windows are open is advice that cannot be taken too liberally.

Therefore, bioentrepreneurs must spend considerable energies on cultivating financial resources for their young companies. Perhaps the best advice on the general subject of capitalization was offered to me in the early 1980s by Bill Hambrecht, (Hambrecht \& Quist, New York), a venerable figure in the biotechnology financial sector. "When the cookie jar comes around," he said, "grab as many cookies as you can-you don't know when it will come around again."

This advice is especially true today when launching a biotechnology company requires many multiples of what it cost in the 1980s. When one considers that it costs, on average, over $\$ 300$ million to develop a single product, and first-tier companies have had to raise $\$ 600$ million or more before gaining operating profitability, grabbing lots of cookies of different flavors, shapes and sizes becomes an economic imperative.

Although many biopharmaceutical companies are launched through private invest- 
ment, venture capital leading to the initial public offering is the more common route by which emerging companies acquire growth financing. It can be a treacherous road for shareholders. Conventional wisdom holds that the several rounds of financing required to capitalize a new biotechnol-

\section{Case study: Centocor}

Centocor began operations in 1979 by developing diagnostic products based on monoclonal antibody technology. Much of this technology had been licensed from The Wistar Institute, a scientific research institution located in Philadelphia. In order to maximize its scientific relationship with Wistar, the company established its laboratory facilities nearby at the University City Science Center. Within four years, Centocor had created a profitable business, having developed such cancer diagnostic products as CA-19-9, CA-125, and CA-15-3. In his role as head of the diagnostics division, David Holveck, present chief executive officer, advanced the growth of the business to a level of approximately $\$ 40$ million per year.

In 1986, Centocor embarked on a new journey in biotechnology. With a successful diagnostics business anchoring its position in the marketplace, Centocor repositioned itself as a biotechnology company. Through the aggressive pursuit of licenses for new discoveries from academic institutions, Centocor amassed a rich coffer of potential product candidates. Both 17-1A, or Panorex, and HA$1 \mathrm{~A}$, or Centoxin, were evaluated as the company's first biotechnology products, but it was Centoxin that emerged as the initial launch candidate.

\section{Lessons learned}

Centoxin was a human antibody whose primary application was in the treatment of sepsis resulting from Gram-negative bacterial infection. A devastating condition leading to irreversible organ failure, sepsis accounts for nearly 80,000 deaths per year. Centoxin acted on the root cause of mortality: It neutralized the endotoxin produced by Gram-negative bacteria. Early work by Ziegler et al. ${ }^{2}$ suggested the potential utility of a polyclonal antibody mixture in the treatment of sepsis. Further in vitro studies with Centoxin demonstrated the increased effectiveness of the monoclonal antibody, and these results provided the impetus to develop the drug.

With a study design identical to the favorable polyclonal study, a clinical trial was initiated to establish unequivocally the efficacy of the Centoxin in the treatment of sepsis. The company positioned itself for success by investing early in a commercial infrastruc- ogy company will undesirably dilute shareholder interest. Further dilution occurs through the initial public offering, a transaction that is ultimately necessary to bring the company to full operating profitability. In the end, however, dilution is never the issue. Raising sufficient capital is the issue.
The word "dilution" should be struck from lexicon of biotechnology-speak, particularly as it relates to relatively young companies; undue concern over dilution discourages the taking of appropriate financial risk.

The corporate partnership offers another option to reinforce a company's capital pil- ture, including manufacturing, marketing, and sales. Despite an endorsement by a US Food and Drug Administration (FDA; Rockville, MD) advisory panel, Centocor did not receive FDA approval for this product on the basis of its single clinical trial. The second trial, requested by the FDA to clarify certain results, ultimately failed.

Centoxin's regulatory defeat was a cataclysmic event for Centocor. In selecting its product candidate, Centocor missed an important cue from the medical marketplace: Sepsis had become an increasingly complex disease. It was found to result, not only from a complex cascade of biochemical events, but also from infection originating from multiple sources-including Gramnegative bacteria, viral, and fungal sources.

Further complicating this picture was the fact that new immunosuppressive drugs, which had become a therapeutic mainstay in oncology and transplantation medicine, were a significant factor in multiple infections. Without a highly specific diagnostic test to establish the infectious agent responsible for the sepsis, a single therapy was not predicted to succeed. The difficulty in developing sepsis therapies is illustrated by the fact that 20 clinical trials, conducted by other pharmaceutical companies and academic institutions subsequent to Centocor's trial, also met with failure.

At the time the FDA required the second Centoxin clinical trial, the company's position was financially perilous. Its stock had dropped from a previous high of $\$ 60$ per share in December 1991 to \$6 by April 1992. And with a cash burn rate of about $\$ 50$ million per quarter supporting the corporate infrastructure and its 1,600 employees, few resources remained with which the company could rejuvenate.

\section{Rejuvenation}

It was decisive action taken by the board of directors during the spring of 1992 that ultimately saved the company. Holveck was appointed president. He was issued a directive to reduce cash burn to the lowest possible level. The head count was reduced from 1,600 to 600 . We enlisted the indispensable assistance of Michael Wall, then an emeritus member of the board, in managing Wall
Street, and we negotiated a sales and marketing agreement with Eli Lilly (Indianapolis, IN) to help commercialize Centoxin, in the event of its ultimate approval, and ReoPro, our second biotechnology product under development. After several lean and very challenging years, Centocor began to rebuild. The internal R\&D operation was reorganized and reenergized for its critical role in driving the company's technology capabilities. Monoclonal antibodies, recombinant DNAbased products, and DNA-based products were used to fill the product pipeline.

While Centoxin was never ultimately approved, with the support of Lilly, Centocor did receive FDA approval of ReoPro in 1994, and the product's success has paved the way for Centocor's achievement of operating profitability in late 1996. Lilly has proved to be a superb commercialization partner in both very difficult and very good times. The success of this collaboration, in which the sales and marketing expertise of a pharmaceutical giant were coupled with the product development and clinical trial experience of its technologyoriented partner, confirmed Centocor's decision to capitalize on similar relationships in commercializing its other products.

Centocor entered into a partnership with Glaxo Wellcome (London) for the commercialization of Panorex, a treatment for colorectal cancer that has received approval in Germany. Avakine, our biotechnology product for Crohn's disease, is currently under review at the FDA, and is in final stages of clinical development for the treatment of rheumatoid arthritis. Avakine will be sold directly by Centocor in the US and by a corporate partner in Europe and Japan.

Most recently, we have made our first product acquisition, Retavase, a clot-buster product that we believe will be synergistic with ReoPro. We also expect that Retavase, along with ReoPro, will secure Centocor's position in the acute cardiovascular therapy market.

Today, Centocor is in its best financial and scientific position since it was founded 19 years ago. We are a stronger, but more humble, company. During the coming years, our challenge is to grow revenues, increase profits, and remain innovative. 
lar. A biotechnology company, often lean on resources and experience but long on technology assets, is a logical partner for an established pharmaceutical company. Large pharmaceutical companies, frequently clamoring for new product candidates, bring both development and regulatory expertise, as well as cookies-a.k.a. money-to the table. An early agreement with a large pharmaceutical company can provide financial stability and facilitate the commercialization of the product, providing a significant reduction in risk for the young biotechnology company.

The major downside of this relationship, if a product candidate is successfully developed in the context of such an arrangement, is that the new company may only
Biotechnology companies are uniquely capable of responding to the pharmacoeconomic imperatives of today's healthcare marketplace. challenge for any bioentrepreneur in this time of astonishing opportunity is to maintain a rigorous focus on the chosen product and its underlying technology.

If we consider, for example, that the recombination of DNA and the production of monoclonal antibodies are biotechnology's first and second technology "platforms," - still viable for product development today-then gene-splicing leading to genomics and gene therapy represent the third technology platform. Already the temptation to abandon well-conceived product development strategies based on the first two generations of technologies in favor of the third generation platform technologies is evident. The explosion of activity in genomics is a clear example of this. Relinquishing othroyalty on the product's sales. If the biotechnology company has the capital to wait until it has invested in the product's development and clinical trials, it is in a stronger position to capture a larger share of product sales. This maneuver does, however, expose the company to greater risk.

\section{Technology}

The mid-1970s emergence of technologies based on recombinant DNA and monoclonal antibody technologies, which evolved from the revolutionary work of scientific partnerships such as that of Cohen and Boyer, and Kohler and Milstein, established the foundations for the biotechnology industry. This is the third pillar upon which every company must be built. Today, most biotechnology companies still look first to academia for sources of new technology. Academia provides a particularly fertile ground for harvesting such discoveries, the importance of which cannot be minimized. Most of the experts in either emerging technologies or disease areas reside here. The Bayh-Dole Act, legislation that encourages academic institutions to license discoveries that emanate from federally funded research, will most likely continue to fuel the biotechnology revolution.

Virtually from its inception, every biotechnology company must have a welldefined and well-articulated product focus. Whether directed toward a specific technology or toward a disease area, the company needs a clear vision of its basis for future revenues. What is unique to biotechnology in this regard is that a single product or two may be sufficient to create the foundation for a large, profitable company. The great

nology platforms in favor of those based nascent discoveries will guarantee a long lapse in the introduction of new products.

With today's biopharmaceutical products based exclusively on first and second platform technologies, we must consider the industry as a whole to be in its infancy. But we have far from exhausted the reservoir of potential products to be developed from those early technologies. Third platform technologies applied to knowledge we glean from the role of specific genes in various disease states will, over the course of the next 20 years, create innumerable opportunities to develop beneficial products. Many of these will form the technology pillar of generations of new companies.

\section{Measuring success}

In the United States today, approximately 2,000 biotechnology companies employ about 130,000 people. Of these, approximately 300 companies are publicly held and 1,700 are private. About $\$ 65$ billion has been invested in biotechnology to date. Taken together, the market value of all companies is approximately $\$ 110$ billion $^{1}$. Thus, overall financial returns in this industry can be described as modest to good.

If one gauges the success of these companies through product sales, profitability (earnings per share), and market value fewer than a dozen have been identified as truly successful. These dozen companies, each with market valuations in excess of $\$ 1$ billion, have been categorized as first-tier companies by the investment community. If achieving first-tier valuation defines suc- cess, then this represents a true success rate of $<1 \%$ for the formation of new biotechnology companies during the period from 1975 to 1998 - a sobering statistic.

But statistics are statistics, and market value is not the only measure of achievement. If, for example, one uses as the benchmark of success an internal rate of return of at least $10 \%$, then biotechnology's success rate is much higher-closer to $60 \%$. Why? Financial achievement is often the result of acquisition, merger, early initial public offerings, off-balance sheet financing, and other creative financial structures such as sale of part of the company.

The curious fact about biotechnology is that many companies have delivered adequate investor returns without developing or marketing products. This arsenal of financial gymnastics has also proven extremely useful in making the industry nearly bulletproof. So far, there have been only two bankruptcies industry-wide. Biotechnology's often-discussed low success rate must then be tempered by the understanding that in this industry a company's progression to product sales and profitability is often preempted by terminal financial transactions.

\section{The future}

We live in a society with an insatiable demand for increasingly sophisticated health care that must be provided more cost effectively than ever before. Reforms in the healthcare delivery system have forever altered how we think about new product development. Biotechnology companies are uniquely capable of responding to the pharmacoeconomic imperatives of today's healthcare marketplace.

The product development efforts of tomorrow's biotechnology companies will be science-driven and aimed at early diagnosis, disease prevention, and improved therapeutics. Using the tools of biotechnolgene and molecular levels that will provide us with better, more specific, and less costly products. The emergence of genomics, the process by which genes are linked to specific diseases, is one example of this new direction.

However, as compelling as the opportunities may be, the challenges associated with translating them into meaningful commercial products will remain daunting. Bioentrepreneurs who can build a company grounded on the three pillars of management, capital, and technology, will provide the next generation of "successes" in biotechnology's rapidly evolving history.

1. Burill, S. Personal communication

2. Brande and Ziegler. 1982. New Engl. J. Med. ogy, therapies can now be developed at the 